\title{
NUMERICAL ASSESSMENT OF THE BACKWARD FACING STEPS
} NOZZLE

\author{
Mohamed M. Eldeeb ${ }^{1}$, Shaaban Abdallah ${ }^{2}$ \\ ${ }^{1}$ Senior Researcher, Technical Research Center, Cairo, Egypt \\ ${ }^{2}$ Professor, Department of Aerospace Engineering, University of Cincinnati, Ohio, USA
}

\begin{abstract}
The backward facing steps nozzle (BFSN) is a flow adjustable exit area nozzle for large rocket engines. It consists of two parts, the first is a base nozzle with small area ratio and the second part is a nozzle extension with surface consists of backward facing steps. The number of steps and their heights are carefully chosen to produce controlled flow separation at steps edges that adjust the nozzle exit area at all altitudes (pressure ratios). The BFSN performance parameters are assessed in terms of thrust and side loads against the dual-bell nozzle (DBN) with the same pressure ratios and cross sectional areas. The DBN is a two-mode flow adjustable exit area nozzle for low and high altitude. Three-dimensional turbulent flow solutions are obtained for the BFSN indicating that the flow is axi-symmetric and does not generate significant side loads. Further confirmation of the axi-symmetric flow is obtained by comparing the three-dimensional flow with the two-dimensional axi-symmetric solutions. The comparison of the thrust generated over the PR range from 50 to 1500 shows that BFSN generates more uniform and higher thrust than the DBN in the intermediate pressure ratios. At PR 1500 (high altitude), the BFSN thrust is $0.28 \%$ less than the DBN. All numerical solutions are obtained using the Fluent code.
\end{abstract}

Keywords: Backward facing steps nozzle, Turbulent flow in supersonic nozzle, Side load in supersonic nozzle.

\section{INTRODUCTION}

In today's launch vehicles, the main engine usually operates from takeoff at sea level up to high altitudes with very low ambient pressures. To get an optimum performance over the whole trajectory, the nozzle is usually designed for an intermediate operating PR, at which the exhaust flow is adapted to the ambient pressure [1]. This leads to flow separation from the nozzle wall when it operates with overexpanding conditions (sea-level). The separated flow causes side loads due to its unsteady nature and its asymmetrical circumferential distribution [2]. The structural damage caused by the transient nozzle side loads during testing at sea level have been found for almost all rocket engines during their initial development [3]. Many examples for the nozzle failure caused by side loads are mentioned in references $[4,5,6,7]$. As a result, whether during sea-level testing or in flight, transient nozzle side loads has the potential of causing real system failure [3].

One possible solution is to adapt the nozzle contour during flight to changes of ambient pressure mechanically, however the weight and mechanical complexities of such device is a big issue [1]. One of the most promising non-mechanical altitude compensating nozzles is the DBN $[8,9,10]$. It is a combination of two bell nozzles with different exit area ratios. Compared to conventional bell nozzle, the DBN has advantages of providing a stable separated flow at low altitudes and high specific impulse at high altitudes [11]. The main advantage of the DBN is its simplicity because of absence of any movable parts and therefore, its high reliability [12]. However, the DBN suffers from a short time specific impulse loss and a high side load peak during the transition from low to high altitude mode [11, 13]. The specific impulse decrease occurs because the transition from low to high altitude mode occurs at lower altitude than the optimum [11]. While the high side load peak occurs during transition because the flow is potentially separates asymmetrically within the nozzle extension [13]. Many studies have been done on the DBN to understand the transition and side loads generation numerically $[14,15,16$, 17, 18] and experimentally [9, 19, 20, 21]. From the literature survey about the nozzle flow separation and side loads, it can be concluded that the key to decrease the side loads is to control the flow separation at all operating conditions.

In this study, we developed a new nozzle that provides an altitude exit area adaptation. The new nozzle consists of two parts: 1) a conventional bell shape base nozzle with low area ratio, similar to the base of the dual-bell nozzle, and 2) the nozzle extension that consists of backward facing steps. The existence of the backward facing steps guarantees a controlled symmetrical flow separation at the steps edges for all operating altitudes (PRs). At sea level, a controlled symmetrical flow separation occurs at the end of the base nozzle decreasing the exit area and increasing the specific impulse. As the nozzle ascends through the atmosphere, the controlled flow separation moves through the steps edges providing a symmetrical flow separation at all operating altitudes which leads to decreasing the occurrence of side loads. The number of steps and their heights are carefully chosen to produce an effective exit area (at the step edges) suitable to the related operating altitudes. 
Three main advantages that can be obtained from the BFSN compared to the DBN. 1) Perfectly symmetrical controlled flow separation at the steps edges leads to decrease in the side loads on the nozzle walls, and 2) the symmetrical circumferential distribution flow separation makes it possible to use two-dimensional CFD analysis to study the BFSN performance and the flow structure at all operating PRs.

In order to proof these advantages, a complete threedimensional numerical study for the BFSN and the DBN; with same area ratio, throat diameter, and length; are obtained at several operating PRs. Figure (1) shows the geometry of the BFSNs and equivalent dual bell nozzle. The wall pressure distributions over the nozzles walls and the axial velocity contours at the effective exit area have been obtained and used to assess the flow symmetrical distribution for both nozzles at all operating PRs. The flow parameters at the effective exit area are obtained and the thrust forces are calculated for all operating PRs. Finally, the three-dimensional numerical results for the BFSN are compared to the two-dimensional axi-symmetric numerical results.

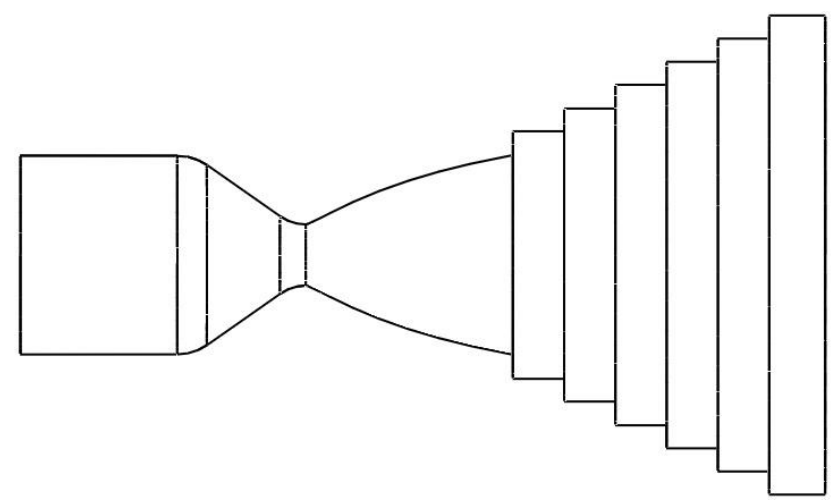

(a)

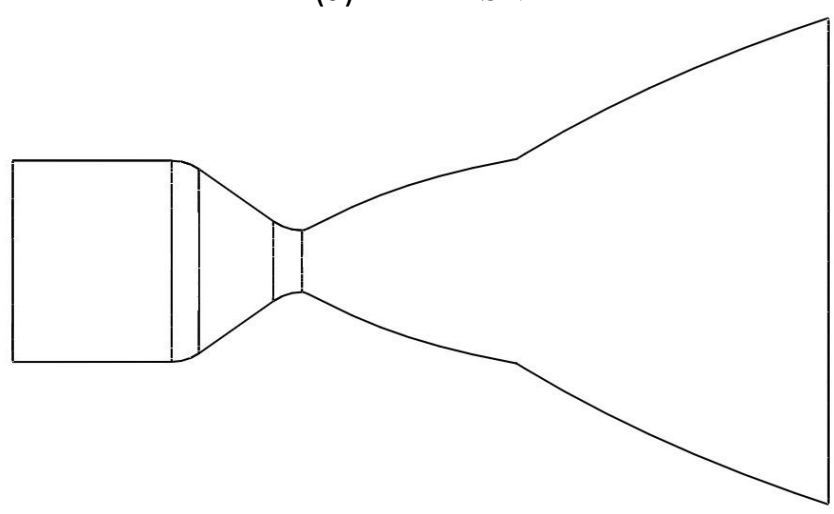

(b)

DBN

Fig -1: schematic diagrams of the nozzles physical models

\section{NUMERICAL METHOD}

The commercial CFD software, Ansys Fluent, is used to simulate the turbulent flow of the sub-scale BFS nozzle and the DBN shown in Figures (1-a) and (1-b). Both nozzles have throat diameters of 0.53 inches and area ratios of 89 .
The length of both nozzles is 5.6 inches. The SST k-omega was utilized to predict the turbulence quantities of the flow field behavior. It was chosen because of its accuracy in computing the flow separation from smooth surface, and predicting the details of the wall layer characteristics [22]. Second order accuracy upwind scheme is used which accurately predicts the interaction between the oblique shock and the turbulent boundary layer. Ideal air is modeled as the driving gas at constant inlet pressure and temperature. Varied ambient pressure is specified at the far downstream boundary. The computations are done using parallel processing on eighteen node cluster at OSC (Ohio Super Computer). Each node is a $2.5 \mathrm{GHz}$ processor.

\section{COMPUTATIONAL DOMAIN AND BOUNDARY CONDITIONS}

The grid of the BFSN and the DBN consist of five blocks for each, two of which located inside the nozzle and the other three are placed outside as shown in Figure (2). A preliminary study was done to determine the downstream distance in the axial and the radial directions for both nozzles at different PRs. It is concluded from that study that the computational domain should be extended to $115 \mathrm{D}$ in the axial direction and $20 \mathrm{D}$ in the radial direction, where $\mathrm{D}$ is diameter of the nozzle throat. Similar computational domain with similar boundary conditions is used for the BFSN and the DBN as shown in Figure (2). To model the flow accurately, the mesh is denser in the turbulent boundary layer and across the geometrical corners to capture the flow separation and the concentrated high flow field gradient. The nozzles walls are assumed to be smooth and adiabatic during the simulations with no-slip and no-flux velocity conditions imposed at the walls. A grid dependence studies are conducted here using the 3-D grids at an operating PR of 800 for both the BFSN and the DBN respectively. For the BFSN, the difference in the average velocity and average static pressure values at the nozzle exit between the fine grid $(4,424,040$ grid points) and the coarse grid $(1,532,487$ grid points) did not exceed $2 \%$ (in average flow velocity). A grid size of 2,212,020 grid points is used in the numerical solution which has an error less than $0.5 \%$ (in flow velocity) compared to the fine grid. For the DBN, the maximum difference in the flow parameters (velocity and pressure) between the fine grid $(3,412,547$ grid points) and the coarse grid $(1,499,050$ grid points) did not exceed $1.8 \%$ (in flow velocity). A grid size of $1,998,478$ grid points is used in the numerical solutions with an error less than $0.7 \%$ (in flow velocity) compared to the fine grid. Figures (3) and (4) show the grid in the mid-plane ( $x-y$ plane of symmetry) inside the BFSN and the DBN respectively.

The quality of the flow solution depends upon the ability to capture the flow phenomena inside the boundary layers that are developing along the solid walls. Fluent recommends locating the nearest grid point along the wall at a distance that corresponds to parietal coordinate $\mathrm{Y}+$ near one for the SST k-lomega turbulent model [22]. The first cell distance from the wall is 1.5 micrometer for both the BFSN and the DBN. From the numerical results, the calculated $\mathrm{Y}+$ average 
is less than 0.8 , and 0.75 for the BFSN and the DBN respectively, that confirm the requirement that $\mathrm{Y}+$ should be near one.

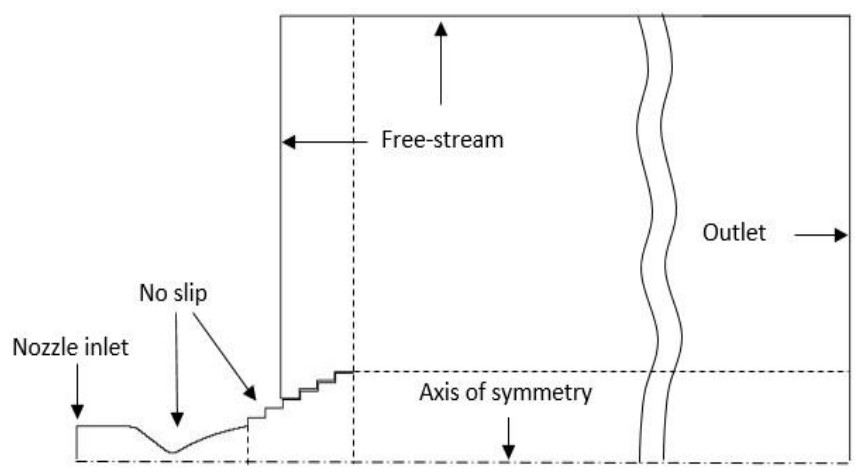

Fig -2: Cross-section shows the computational domain and the boundary conditions

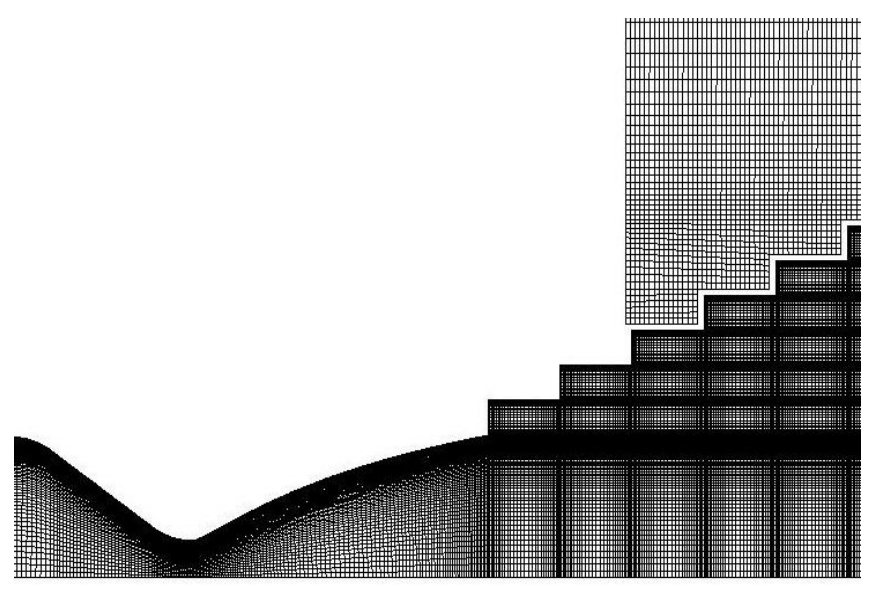

Fig -3: Computational grid inside the BFSN at mid-plane section

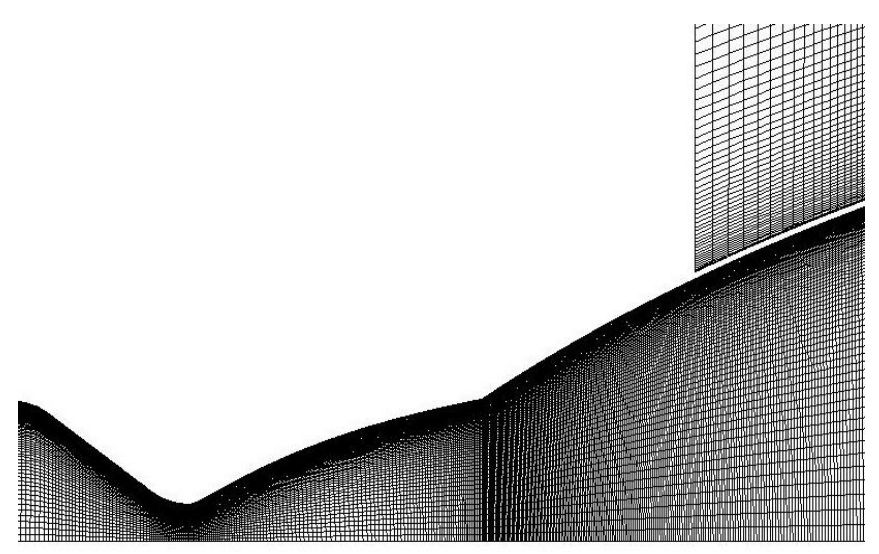

Fig -4: Computational grid inside the DBN at mid-plane section

\section{RESULTS AND DISCUSSION}

Numerical solutions are obtained for both the BFSN and the DBN at different operating PRs for assessment of the BFSN performance against the DBN. Nozzles inlet total pressure of $15 \mathrm{MPa}$ and total temperature of $2000 \mathrm{~K}$ are used with varied back pressure to simulate the different operating PRs.
The pressure distribution over the nozzles walls are plotted for each PR at different azimuth angles. Studying the effect of the 3-D geometry is obtained by detecting the flow separation location around the nozzles circumferences.

The pressure distributions over the BFSN and the DBN walls at azimuth angel \phi equal 0, 90, 180, and 270 degree are plotted and compared to each other for PRs of 400 and 600. The results show that the pressure distributions are identical at all azimuth angels for the BFSN which lead to a symmetrical flow behavior and flow separation location over the nozzle circumferential as shown in Figures (5), (6), (7) and (8). In these Figures, sudden drops in the pressure occur at the discontinuity points of the nozzle surface which is caused by expansion of the flow due to sudden change in the nozzles cross-sectional area. On the other hand, the pressure distribution over the DBN wall showed an asymmetrical behavior leads to a difference in the flow separation locations over the nozzle circumference as shown in Figures (9), (10), (11), and (12). Similar sudden pressure drops occurs in the DBN at the wall inflection point. The maximum difference in the flow separation position is found to be about $4 \%$ and $9 \%$ for PR 400 and 600 respectively.

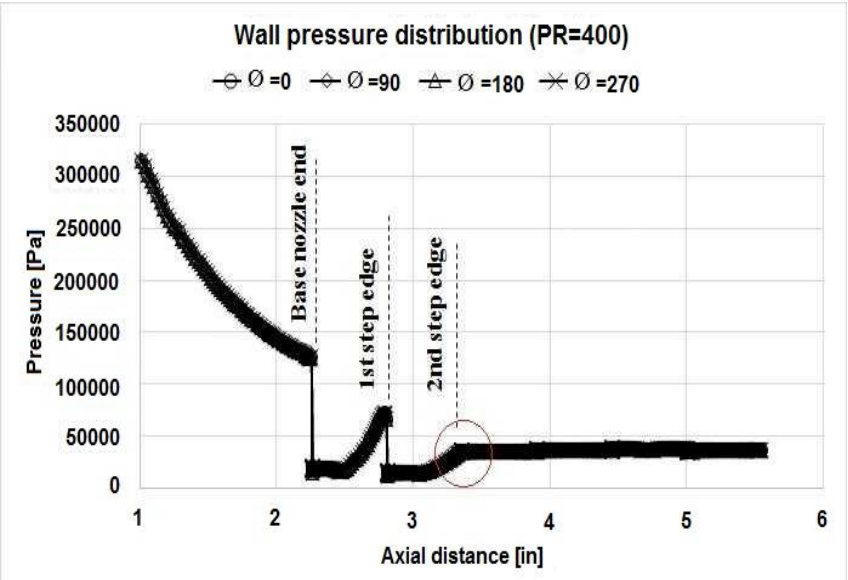

Fig -5: Wall pressure distribution at different azimuth angels for $\mathrm{PR}=400$

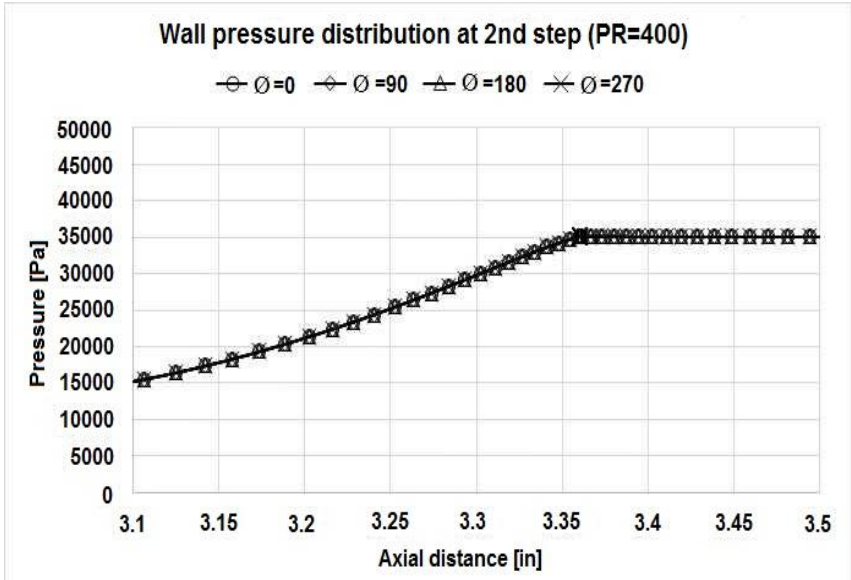

Fig -6: Wall pressure distribution at different azimuth angels for $\mathrm{PR}=400$ zoomed at 2 nd step 


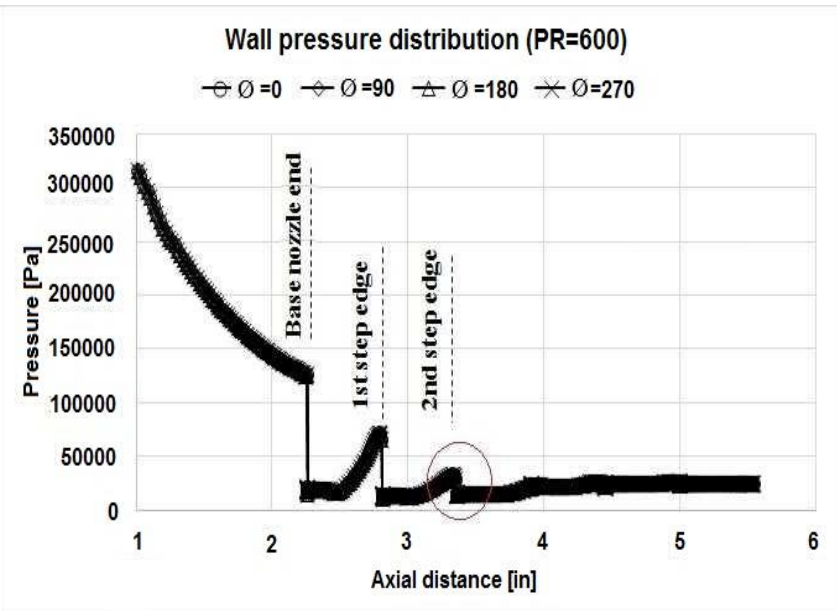

Fig -7: Wall pressure distribution at different azimuth angels for $\mathrm{PR}=600$

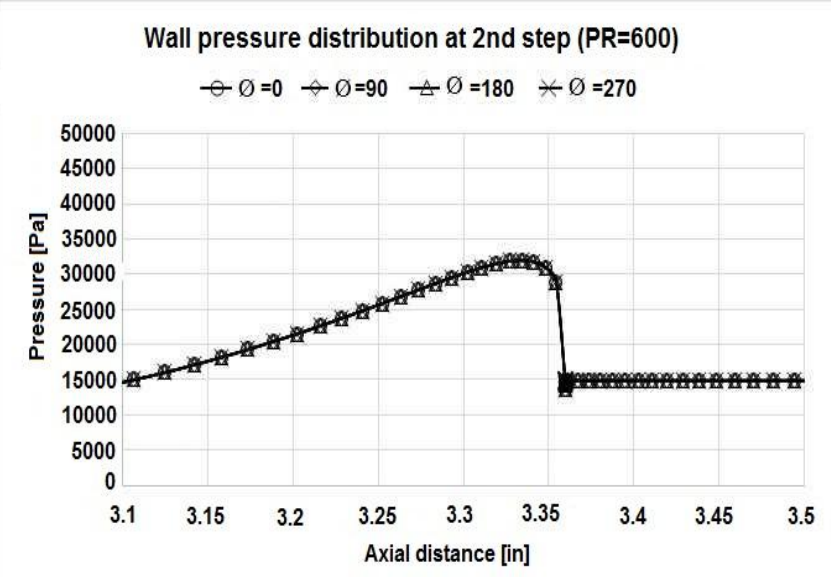

Fig -8: Wall pressure distribution at different azimuth angels for $\mathrm{PR}=600$ zoomed at 2nd step

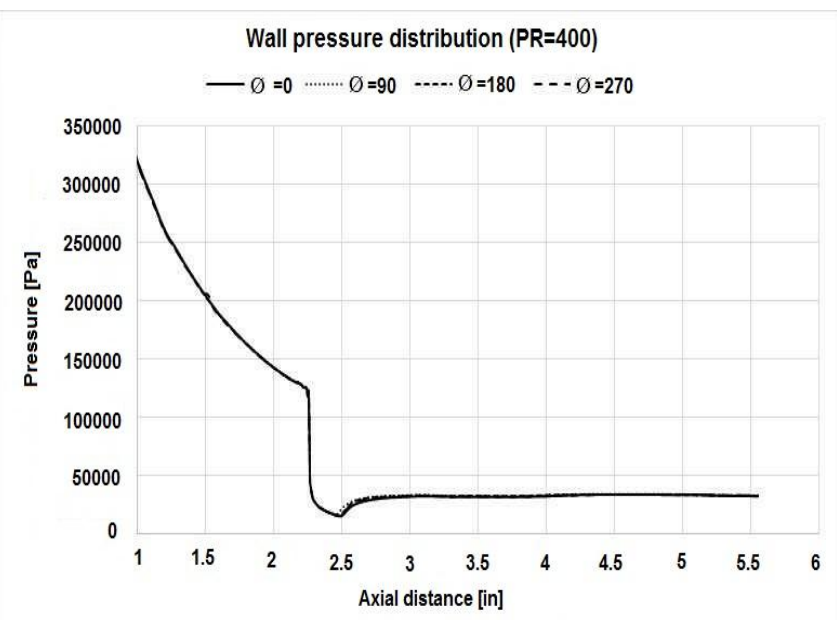

Fig -9: Wall pressure distribution at different azimuth angels for $\mathrm{PR}=400$

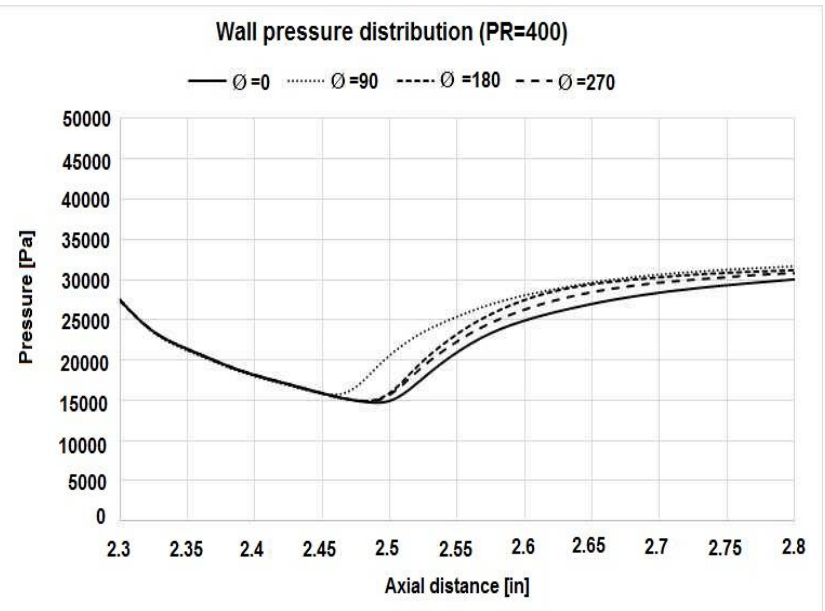

Fig -10: Wall pressure distribution at different azimuth angels for $\mathrm{PR}=400$ zoomed at separation location

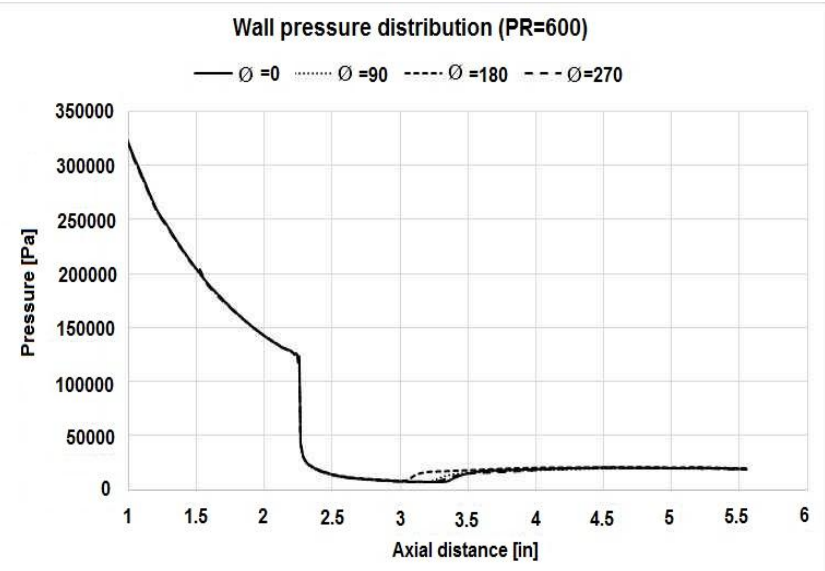

Fig -11: Wall pressure distribution at different azimuth angels for $\mathrm{PR}=600$

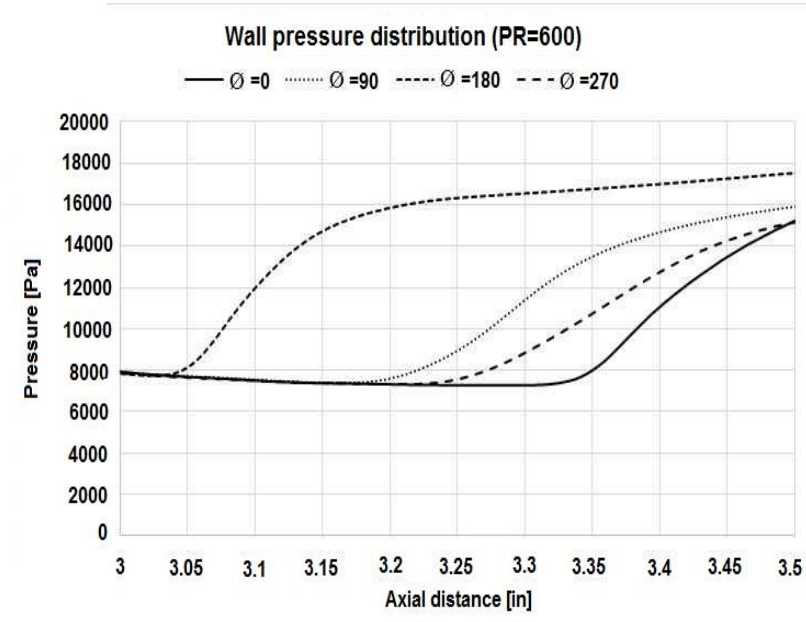

Fig -12: Wall pressure distribution at different azimuth angels for $\mathrm{PR}=600$ zoomed at separation location

Mach contours in the plane of symmetry for PR 400 and 600 are plotted for both the BFSN and the DBN as shown from Figures (13) to (17). The symmetrical nature of the flow inside the BFSN can be noticed from the Mach contours for both PRs of Figures (13) and (14). The BFSN Mach contours show that the flow separation occurred at the 
second step for PR 400 and 600. Figure (15) shows the subsonic region in the flow circulation zone near the first steps corner for PR 600. Similar flow behavior and Mach contours distribution appears at all closed subsonic recirculation zones at all operating PRs. The nozzle effective exit area is the last nozzle cross-sectional area where the flow is separated for a given PR. The flow parameters at the effective exit area are used to calculate the nozzle thrust at different PRs. The asymmetric flow separation inside the DBN can also be noticed from the Mach contours as shown in Figures (16) and (17). The Mach contours show an asymmetric distribution behavior around the nozzle axis of symmetry which shows that the flow inside the DBN is asymmetric.

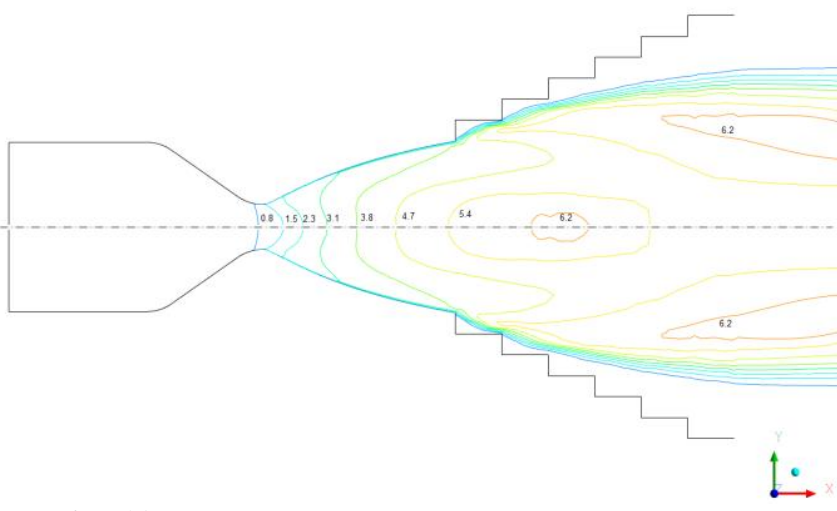

Fig -13: Mach contours at $x-y$ plane of symmetry for $\mathrm{PR}=400$

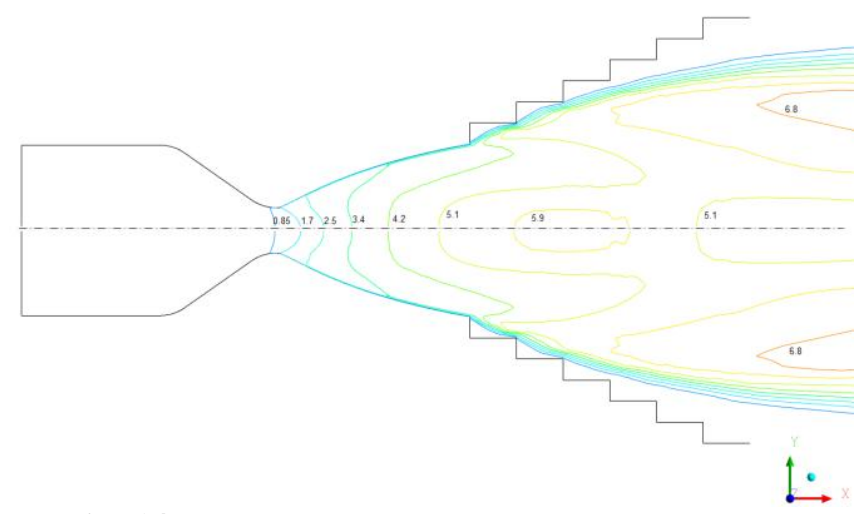

Fig -14: Mach contours at $x-y$ plane of symmetry for $\mathrm{PR}=600$

Fig -15: Mach contours at $x-y$ plane of symmetry for $\mathrm{PR}=800$ zoomed at 1 st step

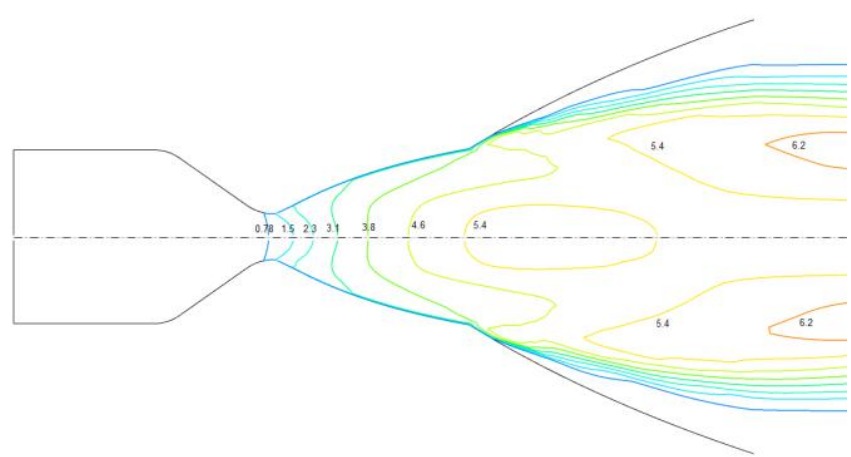

Fig -16: Mach contours at $x-y$ plane of symmetry for $\mathrm{PR}=400$

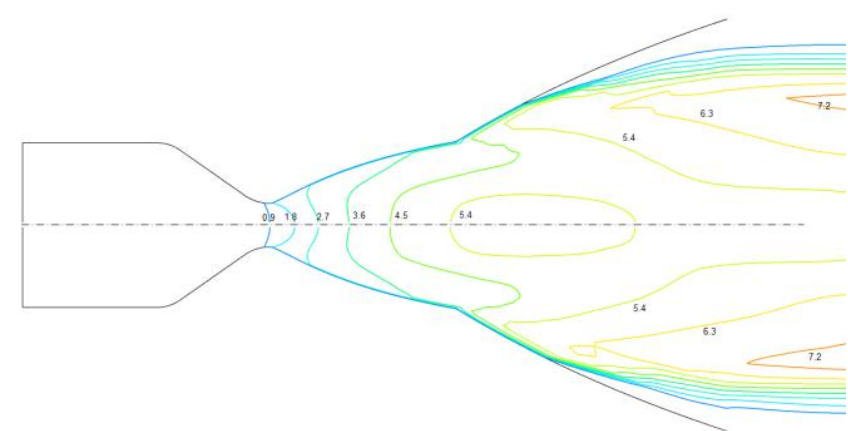

Fig -17: Mach contours at $x-y$ plane of symmetry for $\mathrm{PR}=600$

Further confirmation of the flow behavior inside the BFSN and the DBN is obtained by plotting the axial velocity contours at the nozzle effective exit cross-sectional area shown in Figures (18), (19), and (20). Figures (18) and (19) show the cross-sectional axial-velocity contours, for PR 800 , at the third step where the flow is still attached to the nozzle wall (with minimum positive axial-velocity value near the wall) and the fourth step where the flow is separated from the nozzle wall (with minimum negative axial-velocity value near the wall) respectively. The results show a smooth and axi-symmetric velocity distribution for both attached and separated flow cross-sections. The axial velocity contours at the DBN effective exit cross-sectional area show an asymmetrical distribution for PR 600 as shown in Figure (20).

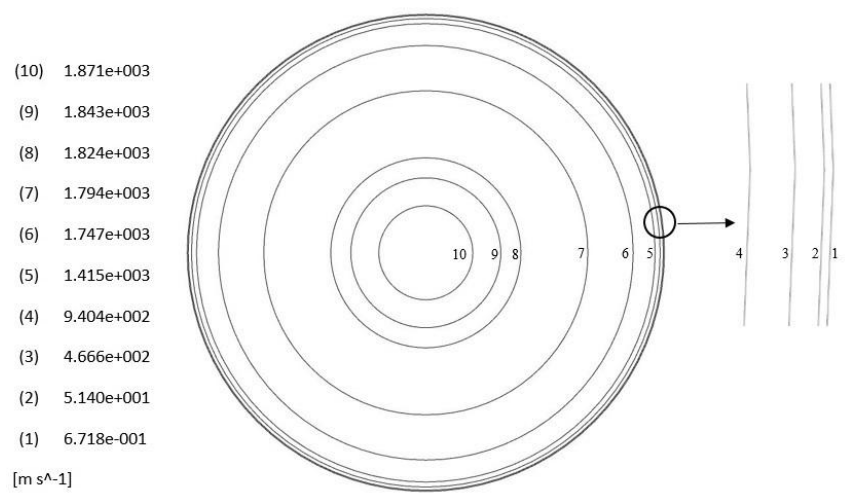

Fig -18: Axial-velocity contours for $\mathrm{PR}=800$ at third steps exit 


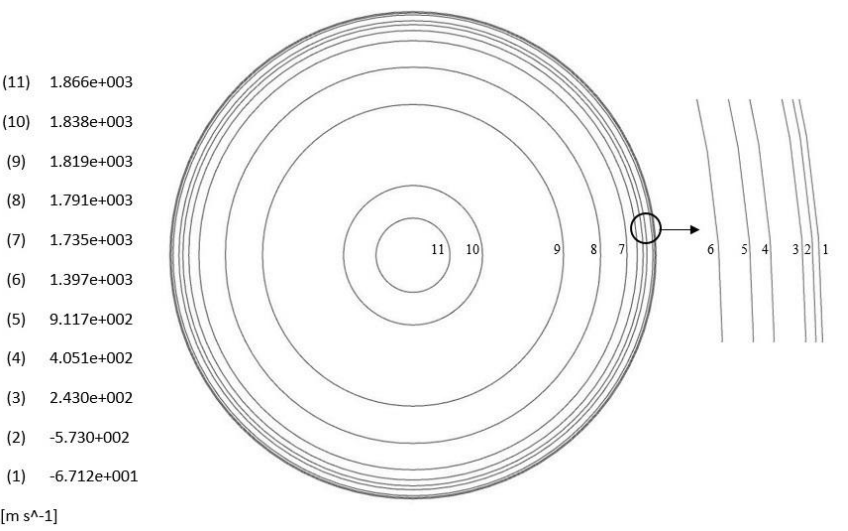

Fig -19: Axial-velocity contours for $P R=800$ at fourth steps exit

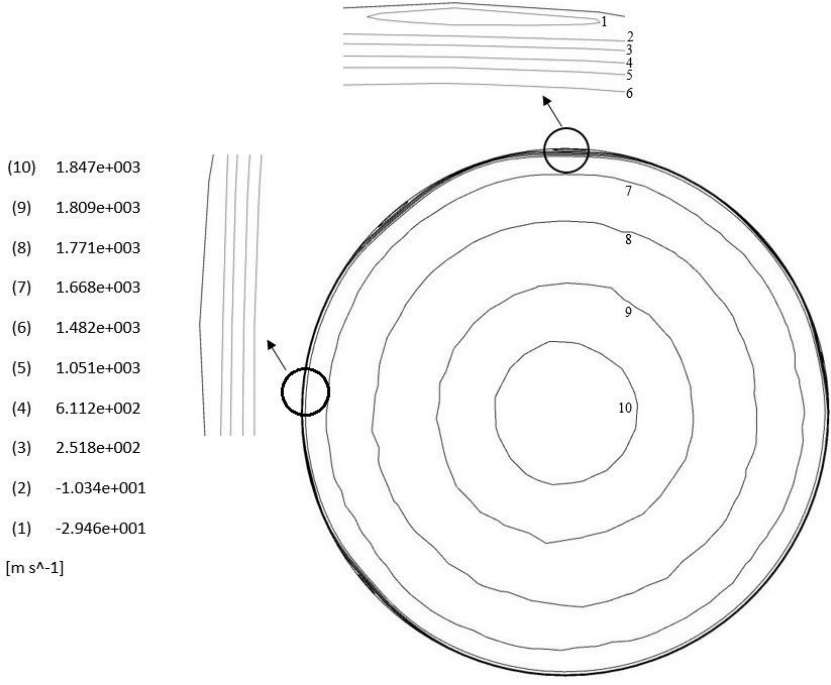

Fig -20: Axial-velocity contours at effective exit area for $\mathrm{DBN}$ at $\mathrm{PR}=600$

For further confirmation of the axi-symmetric nature of the flow in the BFSN, two-dimensional axi-symmetric solutions are obtained computational grid identical to the 3-D grid plane of symmetry. Comparison between the 3-D and the 2$\mathrm{D}$ axisymmetric results are shown in table (1). The flow separation position from the 3-D simulations for each PR shows a good agreement with its position in the 2-D axisymmetric simulation for same PR (at same step edge). The flow parameters at the flow separation location crosssectional area are calculated the 3-D and the 2-D solutions and compared to each other in table (1). The maximum difference between the 3-D and the 2-D solutions is less than $1 \%$.

From these results, we conclude that the flow inside the BFSN is axi-symmetric. That is a very important finding which has the following implications: 1) two dimensional solution can be used to analyze the BFSN, calculate the nozzle thrust, the flow exit velocity, etc., 2) unsteady flow solution are now possible because of the major reduction of the CPU time for 2D solutions compared to 3D solution, and 3 ) the axisymmetric solution is suitable for design practices of unsteady flow.
Table -1: Flow parameters comparison between 3-D and 2D simulations

\begin{tabular}{|c|c|c|c|c|}
\hline PR & Parameter & $3-\mathrm{D}$ & $2-\mathrm{D}$ & $\begin{array}{l}\text { difference } \\
\%\end{array}$ \\
\hline \multirow{3}{*}{400} & $\begin{array}{l}\text { Effective exit } \\
\text { area location }\end{array}$ & 2nd step & 2nd step & \\
\hline & Pressure $[\mathrm{Pa}]$ & 2457.65 & 24803.0 & 0.84 \\
\hline & $\begin{array}{l}\text { Velocity } \\
{[\mathrm{m} / \mathrm{s}]}\end{array}$ & 1731.24 & 1722.33 & -0.51 \\
\hline \multirow{3}{*}{600} & $\begin{array}{l}\text { Effective exit } \\
\text { area }\end{array}$ & 2nd step & 2nd step & \\
\hline & Pressure $[\mathrm{Pa}]$ & 23874.1 & 24097.4 & 0.93 \\
\hline & $\begin{array}{l}\text { Velocity } \\
{[\mathrm{m} / \mathrm{s}]}\end{array}$ & 1748.48 & 1739.36 & -0.52 \\
\hline \multirow{3}{*}{800} & $\begin{array}{l}\text { Effective exit } \\
\text { area }\end{array}$ & 3rd step & 3rd step & \\
\hline & Pressure $[\mathrm{Pa}]$ & 15942.1 & 16089.4 & 0.92 \\
\hline & $\begin{array}{l}\text { Velocity } \\
{[\mathrm{m} / \mathrm{s}]}\end{array}$ & 1735.14 & 1723.27 & -0.68 \\
\hline \multirow{3}{*}{1100} & $\begin{array}{l}\text { Effective exit } \\
\text { area }\end{array}$ & 4th step & 4th step & \\
\hline & Pressure $[\mathrm{Pa}]$ & 11247.2 & 11330.7 & 0.74 \\
\hline & $\begin{array}{l}\text { Velocity } \\
{[\mathrm{m} / \mathrm{s}]}\end{array}$ & 1745.48 & 1733.49 & -0.68 \\
\hline
\end{tabular}

\subsection{Side Loads Calculation}

The side loads are calculated for the BFSN and the DBN at different PRs from the three-dimensional solutions by integrating the pressure over the nozzles walls at the operating PRs 400, 600, and 800 . It has been found that the side loads in the BFSN is $2.3 \%$ of the side loads in the DBN at PR 400, 2.35\% at PR 600, and 2.45\% at PR 800. Note that these results are obtained for scaled nozzles. We expect the values of the side loads in actual nozzles to be much higher. Table (2) shows the side load values in $y$ - and $z$ directions for different PRs for the DBN and the BFSN.

Table -2: Side load values for DBN and BFSN

\begin{tabular}{|l|l|l|l|l|}
\hline PR & Direction & DBN [N] & BFSN [N] & $\%$ \\
\hline \multirow{4}{*}{400} & $\mathrm{y}$ & 2.279 & 0.044 & \\
\cline { 2 - 5 } & $\mathrm{z}$ & 1.5366 & 0.045 & \\
\cline { 2 - 5 } & total & 2.74 & 0.063 & 2.31 \\
\hline \multirow{4}{*}{600} & $\mathrm{y}$ & 2.047 & 0.038 & \multirow{1}{*}{} \\
\cline { 2 - 4 } & $\mathrm{z}$ & 1.57 & 0.047 & \\
\cline { 2 - 5 } & total & 2.58 & 0.060 & 2.35 \\
\hline \multirow{3}{*}{800} & $\mathrm{y}$ & 1.27 & 0.03 & \\
\cline { 2 - 4 } & $\mathrm{z}$ & 2.36 & 0.058 & \\
\cline { 2 - 5 } & total & 2.68 & 0.066 & 2.45 \\
\hline
\end{tabular}




\subsection{Thrust Calculation and Parametric Study}

In order to compare the thrust of the BFSN and the DBN at PR from 50 to 1500 , first the number of the backward facing steps in the BFSN is varied from two-six. The thrust value is found to be highest for the BFSN with two backward facing steps at pressure ratio 1500 as shown in table (3), there for, the thrust curves for the BFSN with two backward facing steps and the DBN are shown in Figure (21). It is important to note here that the thrust curve for the DBN calculated from the 2-D axi-symmetric solutions following many studies have been done using the 2-D axi-symmetric solutions [11], [14], [18], [23], and [24]. The thrust curve is calculated from the flow parameters (pressure and axial velocity) based on the base nozzle exit area before the flow separation point leaves the end of the base nozzle following Refs [8] and [25]. As the flow separation moves downstream toward the nozzle exit, the thrust is calculated based on the nozzle total exit area which takes into account the effect of the flow in the separation region. The thrust curve for the DBN shows large drop in the thrust at $P R=200$ as the flow separation leaves the wall inflection point (base nozzle exit), while the thrust curve for the BFSN experience less thrust drop at $\mathrm{PR}=650$ as the flow separation leaves the base nozzle exit to the first backward facing step edge. As the PR increases, both thrust curves clime up and at $\mathrm{PR}=1500$ the BFSN generates thrust $0.28 \%$ less that the DBN.

Table -3: Thrust values for BFSNs and DBN at $\mathrm{PR}=1500$

\begin{tabular}{|l|l|l|l|l|}
\hline Nozzle & DBN & $\begin{array}{l}\text { BFSN-6 } \\
\text { steps }\end{array}$ & $\begin{array}{l}\text { BFSN-4 } \\
\text { steps }\end{array}$ & $\begin{array}{l}\text { BFSN-2 } \\
\text { steps }\end{array}$ \\
\hline Thrust [N] & 3491.15 & 3485.93 & 3483.96 & 3481.48 \\
\hline $\begin{array}{l}\text { Difference } \\
\text { from DBN } \\
\%\end{array}$ & 0 & -0.17 & -0.23 & -0.28 \\
\hline
\end{tabular}

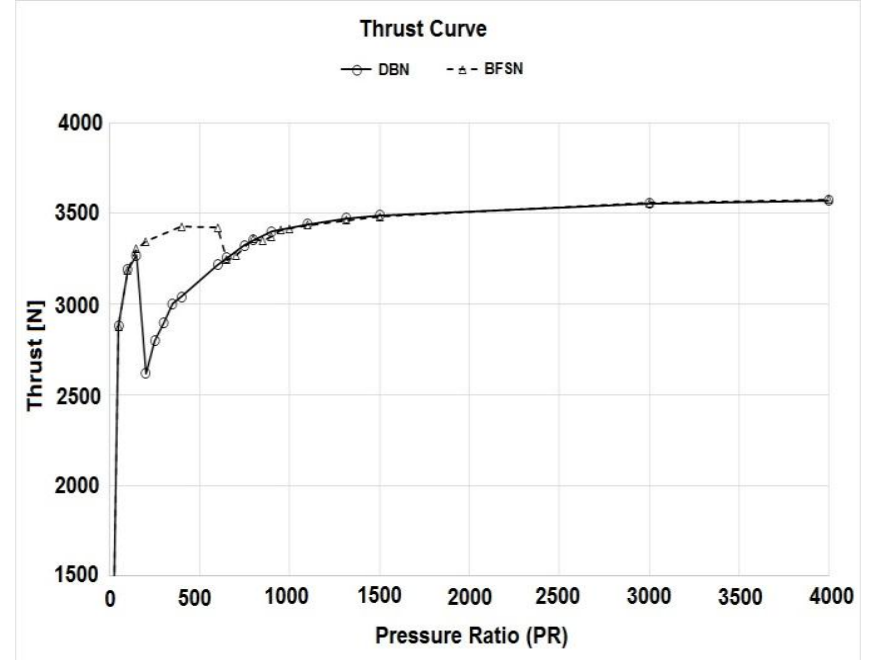

Fig -21: Thrust Curves for the BFSN with two steps and the DBN with respect to PR

\section{CONCLUSION}

New flow adaptive area nozzle with backward facing steps (BFSN) is developed and assessed numerically against to the well-known DBN using Fluent code. The 3-D numerical solutions are used to study the flow behavior inside the BFSN and the DBN at different pressure ratios. The 3-D solutions show that the flow is 3-dimensional in the DBN, and axi-symmetric in the BFSN. This is shown in symmetrical velocity and pressure contours in the crosssectional planes in the BFSN and a non-symmetrical separation in the DBN. Further evidence that confirm the axi-symmetric flow behavior in the BFSN is shown by calculating the 2-D solutions and compare it with the 3-D solutions. Two parameters, the thrust and the side loads generated in both nozzles are used to assess the BFSN against the DBN. The thrust curve for the DBN shows large drop in the thrust at $\mathrm{PR}=200$ as the nozzle mode changes from mode 1 (small nozzle exit area) to mode 2 (large nozzle exit area). Similarly, The change in the BFSN exit area from the base nozzle exit area results in thrust drop that is less than the DBN. At $\mathrm{PR}=1500$ (high altitude), the BFSN thrust is $0.28 \%$ less than the DBN thrust. The side loads are calculated in the BFSN and the DBN and the comparison shows insignificant side loads values generated in the BFSN because the flow is axi-symmetric. Further studies to optimize the performance of the DFSN are required by varying the backward facing steps number, height, and dynamically eliminating the steps. The axi-symmetric flow inside the BFSN is a very important finding which has the following implications: 1) two dimensional solution can be used to analyze the BFSN, calculate the nozzle thrust, the flow exit velocity, etc., 2) unsteady flow solution are possible because of the major reduction of the CPU time for 2D solutions compared to 3D solution, and 3) the axisymmetric solution is suitable for design practices of unsteady flow.

\section{REFERENCES}

[1]. S. B. Verma. Study of flow separation in truncated ideal contour nozzle. Journal of Propulsion and Power, 18(5):1112-1120, September-October 2002.

[2]. Ralf H. Stark and Chloe Genin. Experimental study on rocket nozzle side load reduction. Journal of Propulsion and Power, 28(2):307-311, March-April 2012.

[3]. Ten-See Wang and Mike Guidos. Transient threedimensional side-load analysis of a film cooled nozzle. Journal of Propulsion and Power, 25(6):1272-1280, November December 2009.

[4]. Cikanek H. A. Characteristics of space shuttle main engine failures. AIAA 87-1939, June 1987.

[5]. Watanabe Y., Sakazume N., and Tsuboi M. Le-7 engine nozzle problems during the transient operations. AIAA 2002-3841, July 2002.

[6]. Jone J. Shi. Rocket engine nozzle side load transient analysis methodology - a practical approach. In AIAA 20051860, Austin, Texas, April 2005.

[7]. Winterfeldt L., Laumert B., Tano R., Geneau J. F., Blasi R., and G. Hagemann. Redesign of the vulcain 2 nozzle extension. AIAA 2005-4536, Tucson, AZ, 2005. 
[8]. Manuel Frey and Gerald Hagemann. Critical assessment of dual-bell nozzles. Journal of Propulsion and Power, 15(1):137-143, January - February 1999.

[9]. Gerald Hagemann, Micheal Terhardt, and Dietrich Haeseler. Experimental and analytical design verification of the dual-bell concept. Journal of Propulsion and Power, 18(1):116-122, January-February 2002.

[10]. M. Horn and Fisher S. Dual-bell altitude compensating nozzles. NASA-CR-194719, 1994.

[11]. Dzianis Proshchanka, Koichi Yonezawa, Hidekazu Koga, and Yoshinobu Tsujimoto. Control of operation mode transition in dual-bell nozzles with film cooling. Journal of Propulsion and Power, 28(3):517-529, May-June 2012.

[12]. Gerald Hagemann, Hans Immich, Thong Van Nguyen, and Gennady E. Dumnov. Advanced rocket nozzles. Journal of Propulsion and Power, 14(5):620-634, SeptemberOctober 1998.

[13]. Chloe Genin and Ralf Stark. Side loads in subscale dual bell nozzles. Journal of Propulsion and Power, 27(4):828-837, July-August 2011.

[14]. Chloe Genin, Ralf, Sebastian Karl, and Dirk Schneider. Numerical investigation of dual bell nozzle flow field. 48th AIAA/ASME/SAE/ASEE Joint Propulsion Conference \& Exhibit, editor, AIAA 2012-4164, Atlanta, Georgia, 30 July - 01 August 2012.

[15]. Francesco Nasuti, Marcello Onofr, and Emanuele Martelli. Role of wall shape on the transition in axisymmetric dual-bell nozzles. Journal of Propulsion and Power, 21(2), March-April 2005.

[16]. Francesco Nasuti, Marcello Onofr, and Emanuele Martelli. Numerical study of transition between the two operating modes of dual-bell nozzles. 38th AIAA/ASME/SAE/ASEE Joint Propulsion Conference \& Exhibit, editor, AIAA 2002-3989, Indianapolis, Indiana, 710 July 2002.

[17]. Masafumi Miyazawa and Hirotaka Otsu. An analytical study on design and performance of dual-bell nozzles. 42nd AIAA Aerospace Sciences Meeting and Exhibit, editors, AIAA 2004-380, Reno, Nevada, 5-8 January 2004.

[18]. H. Wong and R. Schwane. Numerical investigation of transition in flow separation in a dual-bell nozzle. 4th Europ Symp. Aerothermodynamics for Space Applications, editor, ESA SP-487, Capua, Italy, 15-18 Oct. 2001.

[19]. Chloe Genin, Andreas Gernoth, and Ralf Stark. Experimental and numerical study of heat flux in dual bell nozzles. Journal of Propulsion and Power, 29(1), JanuaryFebruary 2013.

[20]. C. Genin, R. Stark, and O. Haidn. Experimental and numerical study of dual bell nozzle flow. 4th European Conference for Aerospace Sciences, 2011.

[21]. G. Hagemann, M. Terhardt, D. Haeseler, and Astrium Gmbh. Experimental and analytical design verification of the dual-bell concept. 36th AIAA/ASME/SAE/ASEE Joint Propulsion Conference \& Exhibit, editor, AIAA 2000-3778, Huntsville, AL, 17-19 July 2000.

[22]. Inc. ANSYS. ANSYS FLUENT User's Guide, 14.5 edition, October 2012.

[23]. Emanuele Martelli, Francesco Nasuti, and Marcello Onofri. Effect of wall shape and real gas properties on dual bell nozzle flow field. 41st AIAA/ASME/SAE/ASEE Joint
Propulsion Conference \& Exhibit, editor, AIAA 2005-3943, Tucson, Arizona, 2005.

[24]. Chloe Genin, Ralf Stark, and Dirk Schneider. Transition behavior of dual bell nozzles: Contour optimization. In 49th AIAA/ASME/SAE/ASEE Joint Propulsion Conference, editor, AIAA 2013-3841, San Jose, CA, July 14-17 2013.

[25]. R. Stark, Ch. Bohm, O. J. Haidn, and H. Zimmermann. Cold flow testing of dual-bell nozzles in altitude simulation chamber. 